Quesnel, Y., Sailhac, P., Lofi, J., Lambert, P., Rochette, P., Uehara, M., \& Camerlynck, C. (2021). Multiscale geoelectrical properties of the Rochechouart impact structure, France. Geochemistry, Geophysics, Geosystems, 22, e2021GC010036. https://doi.org/10.1029/2021GC010036

\title{
Multiscale Geoelectrical Properties of the Rochechouart Impact Structure, France
}

\author{
Yoann Quesnel ${ }^{1}$, Pascal Sailhac ${ }^{2}$, Johanna Lofi ${ }^{3}$, Philippe Lambert ${ }^{4}$, Pierre Rochette ${ }^{1}$, Minoru \\ Uehara $^{1}$, and Christian Camerlynck ${ }^{5}$
}

\begin{abstract}
${ }^{1}$ Aix-Marseille Université, CNRS, IRD, INRAE, CEREGE, Aix-en-Provence, France, ${ }^{2}$ Université Paris-Saclay, GEOPS, Orsay, France,

${ }^{3}$ Géosciences Montpellier, Université de Montpellier, CNRS, Montpellier, France, ${ }^{4}$ CIRIR-Center for International Research and Restitution on Impacts and on Rochechouart, Rochechouart, France,

${ }^{5}$ Sorbonne Université, Paris, France
\end{abstract}

\section{Key points}

- All impactite formations of the Rochechouart impact structure have a clear electrical signature

- Large-scale electrical investigations unveil a rough transition between impactites and unbrecciated basement, implying possible megablocks

- Fracturing/brecciation in the Rochechouart basement locally reaches depths larger than $200 \mathrm{~m}$

\section{Supporting Information may be found in the online version of this article.}

Correspondence to: Y. Quesnel, quesnel@cerege.fr

\begin{abstract}
The $205 \mathrm{Ma}$ Rochechouart impact structure (France) is characterized by various impactite formations overlying the Hercynian crystalline basement. New constraints from downhole logging and surface electrical resistivity measurements along $>100 \mathrm{~m}$ long profiles reveal that the top meltbearing breccia layer is more conductive and porous than the underlying melt-poor breccia layer. The stratigraphy within the impactite and the transition with the basement are irregular at small $(\sim 1-10 \mathrm{~m})$ and medium $(>100 \mathrm{~m})$ scales, with vertical amplitude up to $40-50 \mathrm{~m}$. At larger scale $(>1$ $\mathrm{km}$ ), audio-magnetotelluric observations are able to map the lateral and vertical extent of fracturing/brecciation in the basement, reaching $200 \mathrm{~m}$ below the surface nearby Chassenon, in the northern part of the structure. Our results also unveil that the impactite deposits and the brecciated basement of the Rochechouart impact structure may have been shifted laterally and vertically during the modification stage of the impact event through displacements of megablocks, which may be associated with the collapse of a central uplift.
\end{abstract}

\section{Plain Language Summary}

The geological formations of the Rochechouart impact structure are mapped using geoelectrical measurements. The electrical properties of impacted rocks differ significantly from the nonimpacted rocks, thus allowing the imaging of the geological contrasts. Our geophysical study reveals the complex topography of the transition between the impactite and the crystalline basement formations at the bottom of such medium-size impact structure. The lateral and vertical extent of brecciation/fracturation is also investigated using this method, unveiling possible megablocks emplacement throughout a general northward tilting of the crater, which challenges the expected structure of the crater. 


\section{Introduction}

Terrestrial mid-size (apparent diameter $D=10-60 \mathrm{~km}$ ) complex impact structures are usually heavily eroded, and often buried below a post-impact sediment cover or filled by a lake, thus precluding a clear estimate of the crater size (Melosh, 1989). The presence of a central structural uplift is systematic and characterizes this category of craters (Osinski \& Pierazzo, 2013). Osinski et al. (2008) mentioned that massive impact melt rock (IMR) formations are usually observed for crystalline targets while for sedimentary targets, the melt appears more scattered in breccia. The distinction between clast-rich/clast-poor IMR, impact melt-rich/melt-poor breccia, fractured/brecciated basement, and unaffected basement is however difficult for these highly eroded (or buried/underwater/covered by vegetation) structures. Thus the only way to distinguish between these types of units requires drilling and geophysics where impacts are buried. In those cases, geophysics provides a means of investigating the lateral and vertical extent of the impactite formations and of the brecciation/fracturing in the basement. Still numerical models of the sources of geophysical anomalies are limited by non-uniqueness and require additional geological data from drillings or trenches. This is particularly true for models built using potential-field data, which are the most widely used geophysical data for investigating impact structures, since the associated signatures are usually significant (e.g., a circular low gravity anomaly). Other geophysical methods (e.g., seismic reflection and refraction) suffer less from this issue. However, the few examples of electrical investigations over impact structures also reveal the necessity for additional constraints, from drilling to other geophysical data (see Henkel, 1992; Pilkington \& Grieve, 1992), in order to reduce the ambiguity in the geological interpretations of the electrical contrasts.

Among the 27 known terrestrial mid-size complex impact structures in pure crystalline targets (Kenkmann, 2021), Rochechouart is accessible for surface investigations (i.e., not filled by a lake or buried below younger sediments) of the deposits within the crater and the target below. However, the outcrops are sparse due to vegetation and crop fields, and do not allow for a clear 3D representation of the impactite deposits (thickness, lateral extension), the stratigraphic relationships between these impactites and the distribution of the fracturing/brecciation in the basement. In addition, this impact structure has no crater rim preserved, but only shows a relatively flat-lying crater floor (i.e., no central uplift, or it is not in the impactite deposits' area; Lambert, 2010). Therefore, it has prevented a robust estimate of the diameter of the final crater.

Its morphology and the possible regional consequences associated with the impact remain unclear. For instance, concerning its size, the gravity survey described in Pohl et al. (1978) revealed a 20-25 $\mathrm{km}$ wide $-9 \mathrm{mGal}$ Bouguer gravity anomaly. The same data further reprocessed by Schmidt (1984) and Pohl (2015) led to the estimation of a crater in the range of $25-35 \mathrm{~km}$ in diameter, while the geological observations of impactites, shocked basement and damages are only mapped over a 10-12 km wide area (Chèvremont \& Floc'h, 1996; Lambert, 1977; Lambert et al., 2018). In addition, most Rochechouart studies only focused on the impact event dating and/or on the projectile with geochemical observations (Lambert, 2010). Therefore there is no real data and scientific agreements about the processes leading to each impactite type, about the vertical extension and size of the impact crater. Again, only modeling of the gravity data helped to suggest a central $6 \mathrm{~km}$-deep shocked zone (in the basement target) with most damage affecting the first kilometer in the center (Pohl, 2015), while no significant magnetic field anomalies were reported until now in this area. Such uncertainties reveal the need for more geophysical investigations, at all scales. In the fall 2017, in parallel to a drilling campaign performed by the Center for International Research on Impacts and on Rochechouart (CIRIR) in Rochechouart (Lambert et al., 2018), several geophysical surveys started at the same time to better understand this impact structure. This paper reports on the results of electrical investigations. It aims at linking the properties (lithology, porosity, electrical resistivity) of the new core samples with the kilometer scale electrical resistivity 
properties of the Rochechouart impact structure. This allows updating our knowledge of the impactite deposit composition and geometry, and of the fracturing/brecciation extent within the crystalline target for a medium-size impact crater. We first detail the geological context of the Rochechouart impact structure, before introducing the used electrical methods at different scales. The results are then described from sample to field scale, which allows to discuss the electrical properties and the geometry of the geological formations within the impact structure. This work is part of the CIRIR initiative mobilizing the scientific community and the local authorities and institutions on site for valorizing the Rochechouart impact geoheritage (Lambert et al., 2018).

\section{Geological Context}

The Rochechouart impact structure was created around $205 \mathrm{Ma}$ ago (Cohen et al., 2017; Rasmussen et al., 2020; Schmieder et al., 2010) on the crystalline basement of the western Massif Central, a part of the Hercynian Belt. The crater is now eroded down to the bottom of the crater fill deposits that appear in outcrop over a $12 \mathrm{~km}$ diameter area (Figure 1; Chèvremont \& Floc'h, 1996; Lambert, 1977, 2010). The river drainage locally erodes the impactites and exposes the target rocks underneath. The latter is composed by Variscan granitoids and gneiss formations with some isolated mafic units. Despite erosion, the complete sequence of impactites and shock effects expected due to impact in crystalline target are present (Lambert, 2010; Sapers et al., 2014). Out of the brecciated basement, four typical units of impactites were so far described from surface observations: yellow IMR (such as observed on outcrops at Babaudus), red IMR with clastic/glassy matrix (such as observed on outcrops at Montoume), polymict melt-bearing breccia (such as observed on outcrops at Chassenon) and polymict melt-poor breccia (such as observed on outcrops at Rochechouart). In fall 2017, 18 holes (SC1 to SC18 on Figure 1) were drilled at eight sites approximately aligned along two transects across the impact structure. They intercept the major types of impactite lithologies down to the underlying basement (Figure 1). About $540 \mathrm{~m}$ of core were recovered, and the observed lithologies are described in Lambert et al. $(2018,2019)$. The first observations on core samples are in agreement with the various mineralogy and textures exposed over the study area (Chèvremont \& Floc'h, 1996; Kraut \& French, 1971; Lambert, 1977, 2010). They allow refining the thicknesses of each unit forming the impactite deposits and provide more details about the stratigraphic relationships among these units. The deepest $(121 \mathrm{~m})$ drill hole was performed in the Chassenon Butte through the melt-bearing breccia formations in the northern part of the studied area (Figure 1). Lambert et al. (2019) identify four units with distinctive lithological signature from top to bottom: about $40 \mathrm{~m}$ of Chassenon-like melt-rich polymict breccia, $48 \mathrm{~m}$ of Rochechouart-like melt-poor polymict breccia, and $26 \mathrm{~m}$ of essentially monomict breccia overlying about $7 \mathrm{~m}$ of quasi-unbrecciated basement (more detailed geological logs are described in Lambert et al., 2019; some photographs of samples are also shown in Figure S1). Seven other sites distributed along the transects have been drilled down to $65 \mathrm{~m}$ for 6 of them, supplemented by 10 drill holes with maximum depth ranging from 1 to $10 \mathrm{~m}$, all within the breccia deposits (Lambert et al., 2018, 2019). The $65 \mathrm{~m}$ deep hole at the center of the structure near Valette (Figure 1) did not reach the basement. All the other $65 \mathrm{~m}$ deep holes did. The cores from this drilling campaign are made available to the impact science worldwide community through the CIRIR repository settled in Rochechouart, and will serve a variety of research projects aiming at better understanding the impact processes at the bottom of impact structures on crystalline targets (Lambert et al., 2018, 2019). 


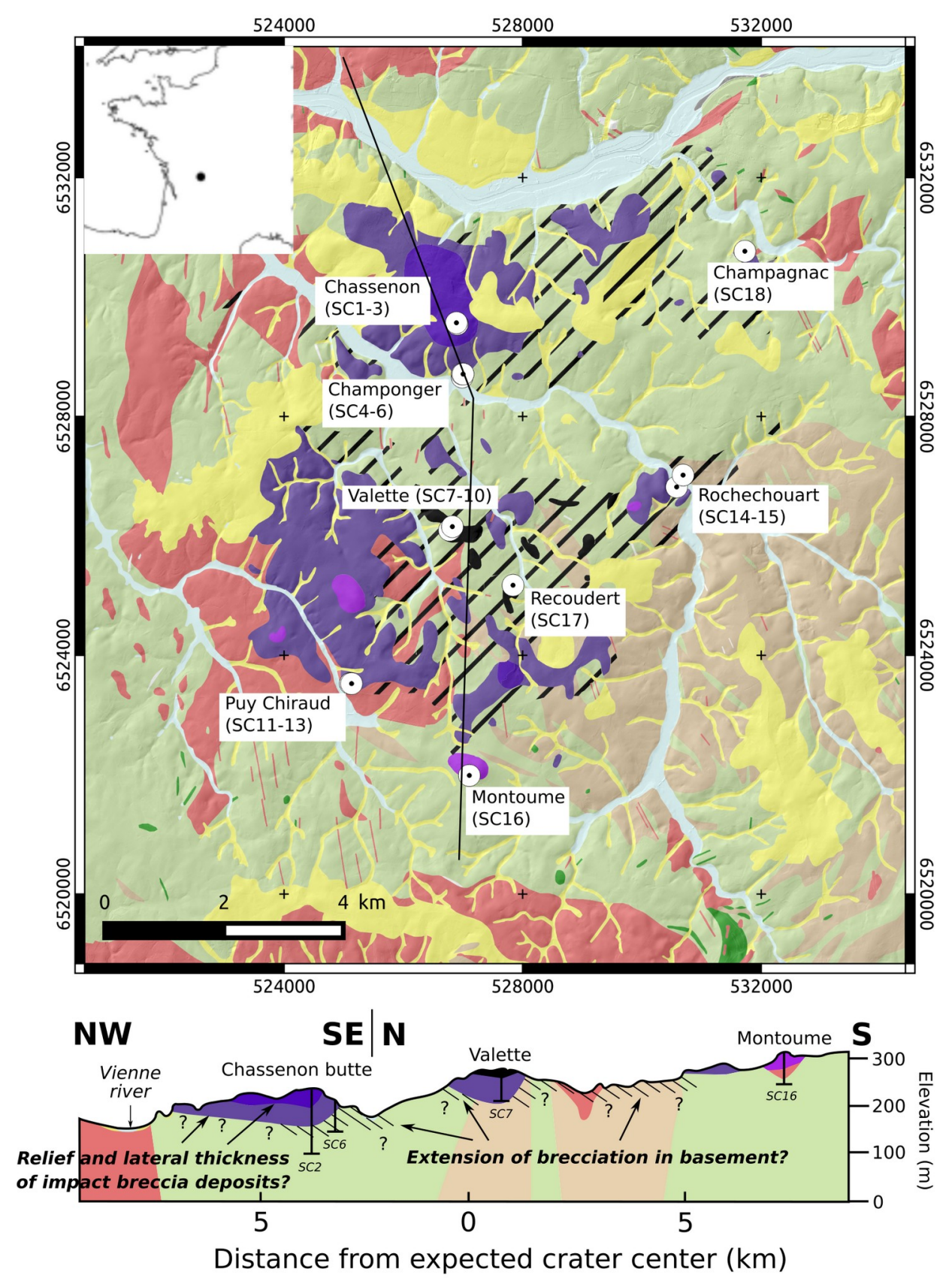

Drilling sites Impactite deposits

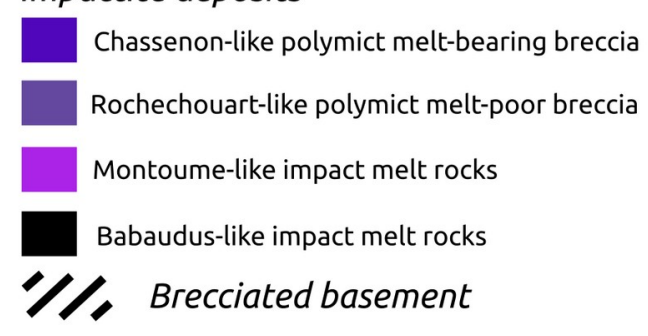

Fluvial deposits

Quaternary formations (incl. alterites)

\section{Basement rocks}

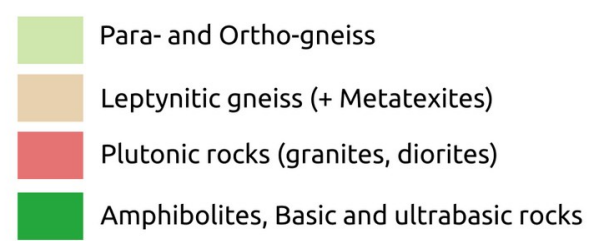

Figure 1. Simplified geological map and associated N-S cross section of the Rochechouart impact structure (modified from Chèvremont \& Floc'h, 1996, and Lambert, 2010), with location of the drilling sites (SC1 to SC18) of the 2017 campaign. Coordinates are in metric units with Lambert 93 projection and RGF93 datum. Geology is draped over a shaded digital elevation model grid with $5 \mathrm{~m}$ pixel size (RGE Alti, product from Institut National de l'information Géographique et forestière). The cross section is modified from Lambert (2010) with 2017 drilling updated information. 


\section{Methods}

In parallel to the initial analyses of the core samples, four methods were used to unveil the electrical resistivity properties and contrasts of the Rochechouart impact structure: downhole logging tools, petrophysical measurements on core samples, electrical resistivity tomography (ERT) and controlled-source audio-magnetotelluric (CS-AMT) measurements (Figure 2; see also Figure S2 for field and instruments photographs). The downhole logging measurements were acquired in the deepest holes in the fall 2018 (Figure 2). The majority of measurements were performed in open borehole conditions (no casing). Among them, electrical resistivity of the formation (composed by its solid matrix plus interstitial fluids) was measured every $5 \mathrm{~cm}$ with a galvanic focused resistivity tool (Geovista DLL3 slimline tool) that provides both deep $(>1 \mathrm{~m})$ and shallow $(<0.5 \mathrm{~m})$ readings and with an electromagnetic induction resistivity probe (EM51 slimline tool). The EM51 was used for air-filled part of the borehole, while the DLL3 system was used below the water table. The EM51 resistivity data were subsequently corrected in order to make the EM51 resistivity curve matching the DLL3 curve by using an exponential correlation derived from intervals where both logs were overlapping. This correction provides good DLL3-equivalent values for the electrical measurements performed in the upper air-filled part of the holes. The porosity of water-saturated core samples was measured using a Quantachrome Helium stereopycnometer after drying each sample at $40^{\circ} \mathrm{C}$ during $24 \mathrm{~h}$. The envelope volume of each sample was determined by scanning a paper with all surfaces drawn and measuring them using a GIS software, while each height was measured using a caliper. We also measured the electrical conductivity of the same samples, which were immersed $24 \mathrm{~h}$ in water with $400 \mu \mathrm{S} / \mathrm{cm}$ of conductivity, like in the SC2 borehole, by using a 3532-50 LCR Hi Tester (Hioki E.E. Corp.) equipped with a test fixture (Figure S2d). A cylindrical sample was installed between the top and bottom stainless steel electrodes (diameter $=4 \mathrm{~cm}$ ). To reduce the polarization between the rock and the steel, acetate filter papers saturated with the same water were placed between the electrodes and the samples. The measured apparent resistance was converted in the resistivity of a cylinder having the same volume with the sample. ERT profiles were performed across each drilling site in order to better map the spatial extent of the drilled lithologies (Figure 2). A 4-channel ABEM Terrameter SAS 4000 Lund imaging system with a Wenner-Schlumberger protocol was used, with 64 electrodes. Spacing of 2, 5, and $10 \mathrm{~m}$ between each electrode allowed profile lengths of 126,315 , and $630 \mathrm{~m}$, respectively. A 32 electrode roll-up protocol was used with $5 \mathrm{~m}$ of electrode spacing for the profile in Valette over SC7-10, which allowed to reach $480 \mathrm{~m}$ of length. Depending on the number of rejected measurements during the acquisition, the raw data sets contain 832 to 920 electrical resistivity observations along these profiles, except for the roll-up profile with 1,520 observations. The raw data of each profile were processed using the RES2DINV resistivity imaging software of Geotomo Software. A L1-norm "robust" inversion method was used to converge on final models. 


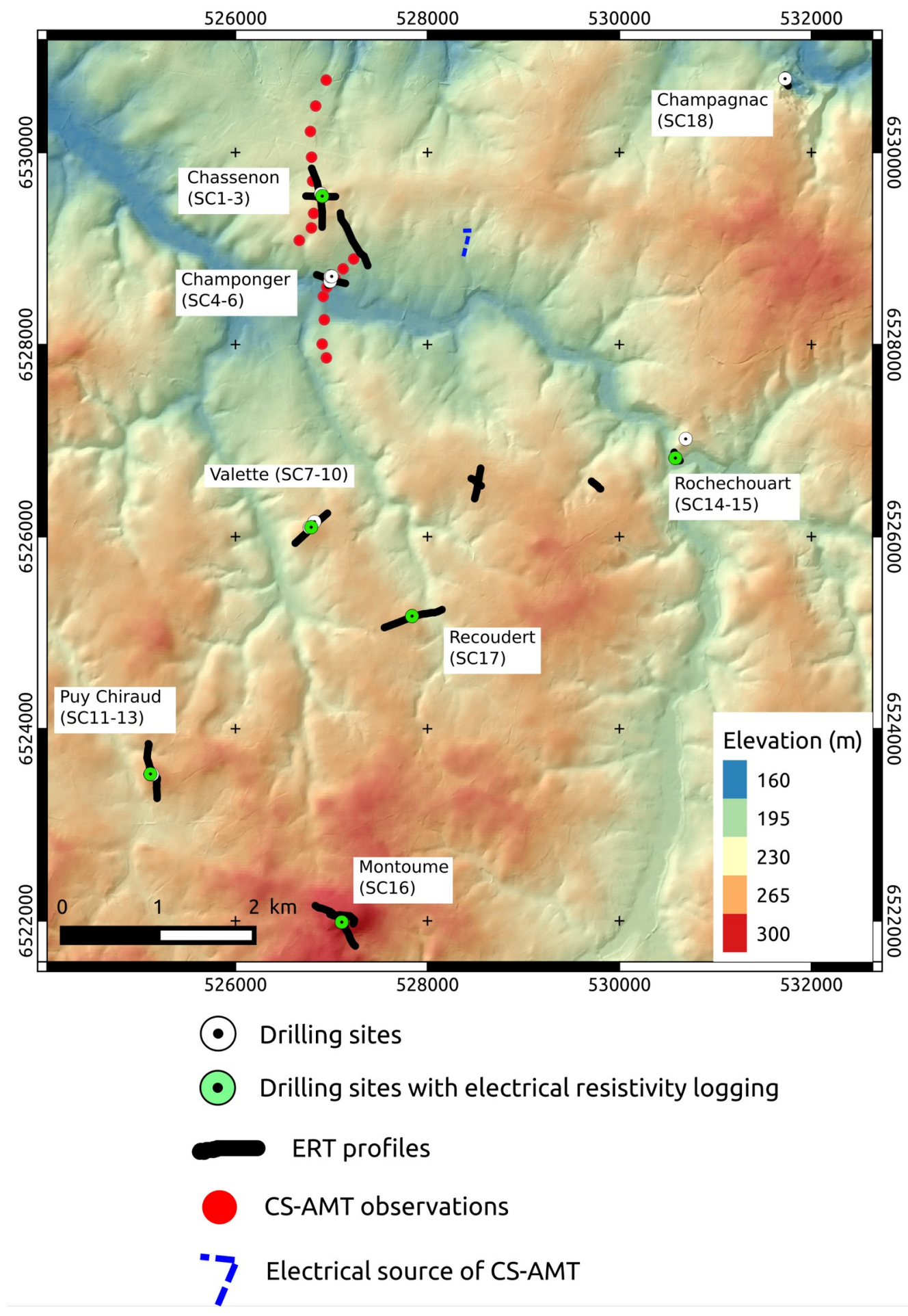

Figure 2. Location of the electrical measurements performed via downhole logging, electrical resistivity tomography (ERT) soundings, and controlled-source audio-magnetotelluric (CS-AMT) data. Background is shaded and colored digital elevation model grid with $5 \mathrm{~m}$ pixel size (RGE Alti, product from Institut National de l'information Géographique et forestière).

CS-AMT measurements were also performed to investigate the fracturing and brecciation at larger penetration depth than the ERT, and mainly to image the electrical resistivity of the brecciated/unbrecciated crystalline basement. AMT is strongly sensitive to ambient electromagnetic fields, mainly those generated by the $50 \mathrm{~Hz}$ local electrical network, but this sensitivity was reduced by using the CS-AMT technique, which increases the signal-to-noise ratio. The GPS-synchronized Phoenix RXU-TMR was used with a T3 transmitter controlling signals at 
frequencies between $512 \mathrm{~Hz}$ up to $9,600 \mathrm{~Hz}$. A N-S profile of 17 measurement stations was acquired running from the north of the Chassenon area to the south of the Champonger area (Figure 2). The distance between the (line of) stations and the transmitter is $2.2 \pm 0.5 \mathrm{~km}$, while the mean spacing between each station is $230 \pm 90 \mathrm{~m}$. Such small distance between AMT stations allowed us to measure the magnetic field signal (with Phoenix AMTC-30 magnetic induction coils, which have noise below $0.01 \mathrm{nT} /(\mathrm{Hz}) 3 / 2$ in AMT band) every three stations only, while the electrical field was measured (with standard copper electrodes) at each station. Significant data processing and inversion were done to make a cross section of stitched $1 \mathrm{D}$ electrical resistivity logs of the earth beneath each observation point. The investigation depth is limited by the conductivity of the shallow lithologies, the distance and angle from the transmitter, and the electromagnetic signal frequencies. Therefore, the 1D inversion of these data led to different vertical extent beneath each observation point.

\section{Results}

Figure 3 shows the vertical variations of the downhole electrical resistivity for the drilling site of Chassenon (hole SC2). It reveals that each layer has its own specific electrical signature. For instance, on average, the conductive melt-rich (50-200 Ohm.m) and the more resistive (100-500 Ohm.m) melt-poor impact breccia layers are contrasted, but both layers remain less resistive than the underlying brecciated gneiss (>200 Ohm.m). Table 1 shows the ranges of electrical resistivity values for the various geological units measured by downhole logging in the deepest holes, and by additional laboratory measurements on core samples from 3 drilling sites (Figure 4). The latter confirm the electrical resistivity contrasts between melt-rich and melt-poor breccias. Porosities larger than $10 \%$ are mainly observed for the Chassenon polymict breccias, up to $17 \%-22 \%$ for some samples (Figure 4). Concerning IMR samples, those of the Puy Chiraud site show electrical resistivities between 80 and $100 \mathrm{Ohm} . \mathrm{m}$, whereas the ones from the Valette site range between 100 and 800 Ohm.m. In the drill holes, the IMR layers of Montoume, Recoudert, Valette, and Puy Chiraud sites show relatively low electrical resistivity values, on the order of $20-200$ Ohm.m (Table 1 and Figure 3). In Chassenon and several other sites, the brecciated basement (here gneiss) yielded downhole logging electrical resistivities between 200 and 2,000 Ohm.m. These values are partially in the same order of magnitude of the ones observed in the polymict melt-poor breccia, but are much lower than the high resistivities (2,000-4,000 Ohm.m) characterizing the unbrecciated gneiss which has only been drilled at the bottom of the Chassenon and Champagnac drilling sites. The transition between the brecciated and unbrecciated gneiss units in Chassenon is associated with a thin cataclasite zone at 112-115 m of depth in hole SC2, which is clearly marked by a reduction of electrical resistivity observed by downhole logging (Figure 3), due to the intense brecciation. Core samples and downhole logs locally permit the identification of the depth at which the transition between the fractured/brecciated basement and the unbrecciated basement of the Rochechouart impact structure occurs. The ERT profiles allow spatial variations of this transition to be imaged. Figure 5 shows four resulting N-S sections, centered on the Chassenon (ERT01 profile), Champonger (ERT02), Recoudert (ERT03), and Valette (ERTO4) drilling sites. The other ERT profiles, with similar ranges of electrical resistivities for the same lithologies, are shown in Figure S3. Percentages of root mean square residuals range between $4.2 \%$ and $7.4 \%$ after the inversion of the apparent electrical resistivity data along these selected four profiles. As expected from the downhole logs, the vertical variations of sub-surface electrical resistivity nearby the drilling sites are well correlated with the stratigraphy. On the ERT01 profile, the conductive $(<100$ Ohm.m) melt-rich breccia are clearly identified above the more resistive (100-1,000 Ohm.m) meltpoor breccia. Moreover, the melt-rich/melt-poor transition is not flat: about $40 \mathrm{~m}$ relief can be observed in the northern part of ERT01. The local resistive dome at the bottom of the ERT01 profile ties with the proximity of the basement (brecciated and unbrecciated gneiss). The ERTO2 
profile clearly images some $>10$ m-wide and thick resistive (800-3,000 Ohm.m) "blocks" overlying the conductive polymict breccia in the northern and central part of the profile, and the resistive (>2,000 Ohm.m) gneissic basement, cropping out to the South. The transition between the breccia and this basement is not flat nor homogeneous, but seems to dip toward the North with sparse basement blocks consolidated by impact breccia, resembling a mega-breccia formation. In the ERTO3 and ERT04 profiles acquired in Recoudert and Valette (Figures $5 \mathrm{e}$ and 5f), the IMR deposits are visible and show electrical resistivities of 50-300 Ohm.m, which are coherent with the downhole log measurements (Table 1). As for Chassenon, the presence of the water table may have slightly reduced the apparent electrical resistivity. Still those values are here close to ones of the melt-bearing breccia (perhaps due to the alteration in clays). In those locations, the impactite deposits are not uniform in thickness, nor lying horizontally, and the bottom interface with the basement is not obvious (with "blocks" rather than "layers").

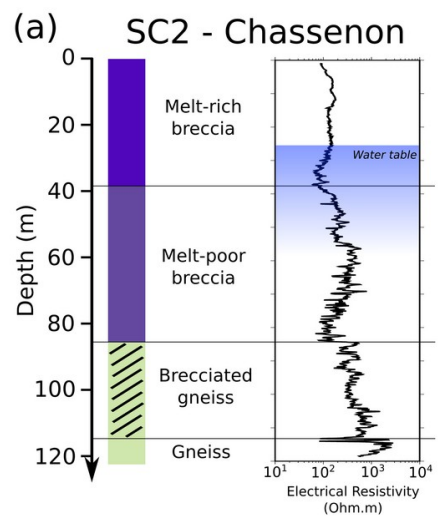

(c)

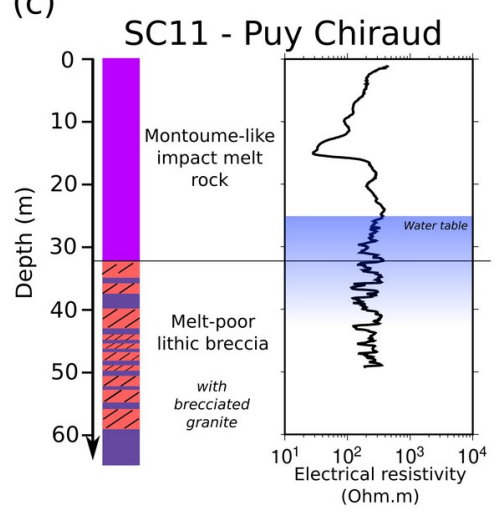

(e)

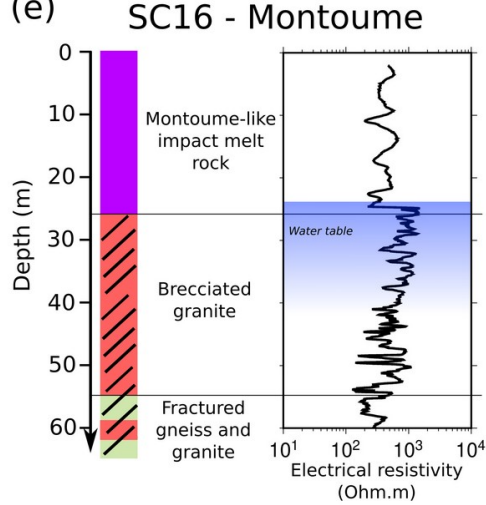

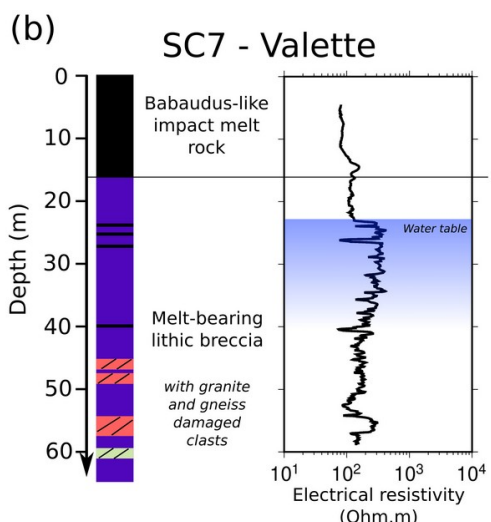

(d)

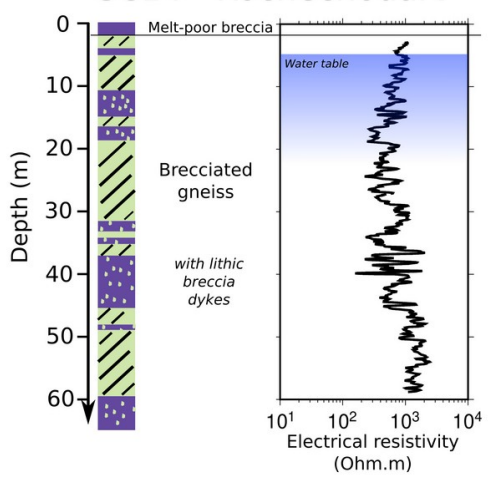

(f)

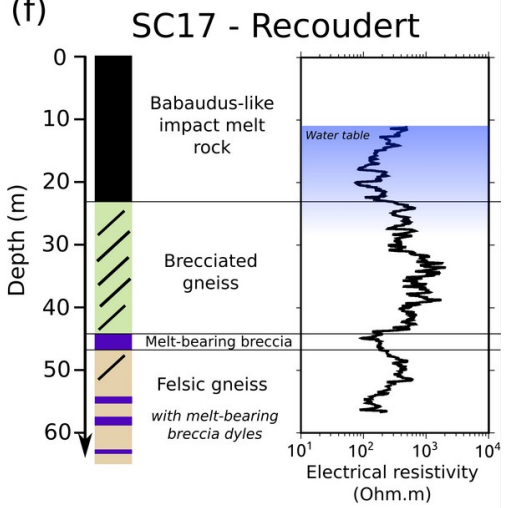

Figure 3. (Left) Synthetic geological log of the drilling sites (from Lambert et al., 2019) and (right) associated downhole logging electrical resistivity of the formations, for (a) SC2 hole in Chassenon, (b) SC7 hole in Valette, (c) SC11 hole in Puy Chiraud, (d) SC14 hole in Rochechouart, (e) SC16 hole in Montoume, and (f) SC17 hole in Recoudert. For resistivity logging, the top part, above the water table, corresponds to rescaled-EM51 data (see text for details). 
Table 1. Ranges of mean electrical resistivity properties of the impactite and basement units

\begin{tabular}{ccccc}
\hline & \multicolumn{4}{c}{ Electrical Resistivity (Ohm.m) } \\
\cline { 2 - 5 } Geological units & $\begin{array}{c}\text { From downhole } \\
\text { logging }\end{array}$ & $\begin{array}{c}\text { From water- }_{\text {saturated samples }}{ }^{a} \\
\text { sarom ERT }\end{array}$ & $\begin{array}{c}\text { From Bobée et al. } \\
\text { profiles }\end{array}$ & $\begin{array}{c}\text { From } \\
(2010)\end{array}$ \\
\hline Impact Melt Rocks & $20-200$ & $80-700$ & $50-300$ & - \\
Melt-rich breccia & $50-200$ & $20-60$ & $10-100$ & $180-240$ \\
Melt-poor breccia & $100-500$ & $80-200$ & $100-1000$ & $100-600$ \\
Brecciated basement & $200-2000$ & $100-400$ & $1000-3000$ & $>600-700$ \\
Unbrecciated basement & $2000-4000$ & $1100-6000$ & - & - \\
\hline
\end{tabular}

ERT: Electrical Resistivity Tomography.

${ }^{a}$ water conductivity $=400 \mu \mathrm{S} / \mathrm{cm}$, which is equivalent to the one measured in SC2 borehole

The CS-AMT data inversion yields to a wide cross section across the Chassenon butte (Figure 6a). At shallow depths, it is possible to observe the melt-rich (resistivities less than $100 \mathrm{Ohm} . \mathrm{m}$; in blue)/melt-poor (resistivities between 100 and 500 Ohm.m; in green) impactite transition (Figures $6 \mathrm{~b}$ and $6 \mathrm{c}$ ). The contrast between the melt-poor polymict impact breccia formation and the brecciated gneiss (200-2,000 Ohm.m; green to orange colors) is less obvious (Figure 6b) and tentatively interpreted as shown in Figure 6c. The relatively "conductive" top layers prevent imaging deeper in the Chassenon butte area, and in particular the transition between the brecciated gneiss and the strongly resistive unbrecciated gneiss. The resistivity values for the brecciated basement also appear to be not greater than about 1,000 Ohm.m when it is covered by other impactites, but its thickness is larger than $200 \mathrm{~m}$. However, southward, where the brecciated gneiss outcrops, the investigation depth increases and reaches about $300 \mathrm{~m}$ in the crystalline basement. Resistivities larger than 2,000 Ohm.m corresponding to the unbrecciated basement are well observed in the valley south of Champonger. Despite these lateral differences of investigation depths, the measurements clearly confirm that there is a significant topography formed by each lithological transition, with sometimes a relief greater than $100 \mathrm{~m}$ (i.e., greater than the variations of the present-day surface topography). On average, taking the vertical exaggeration into account, this CS-AMT section reveals that these transitions dip between $10^{\circ}$ and $30^{\circ}$ northward (i.e., outward from the expected crater center).

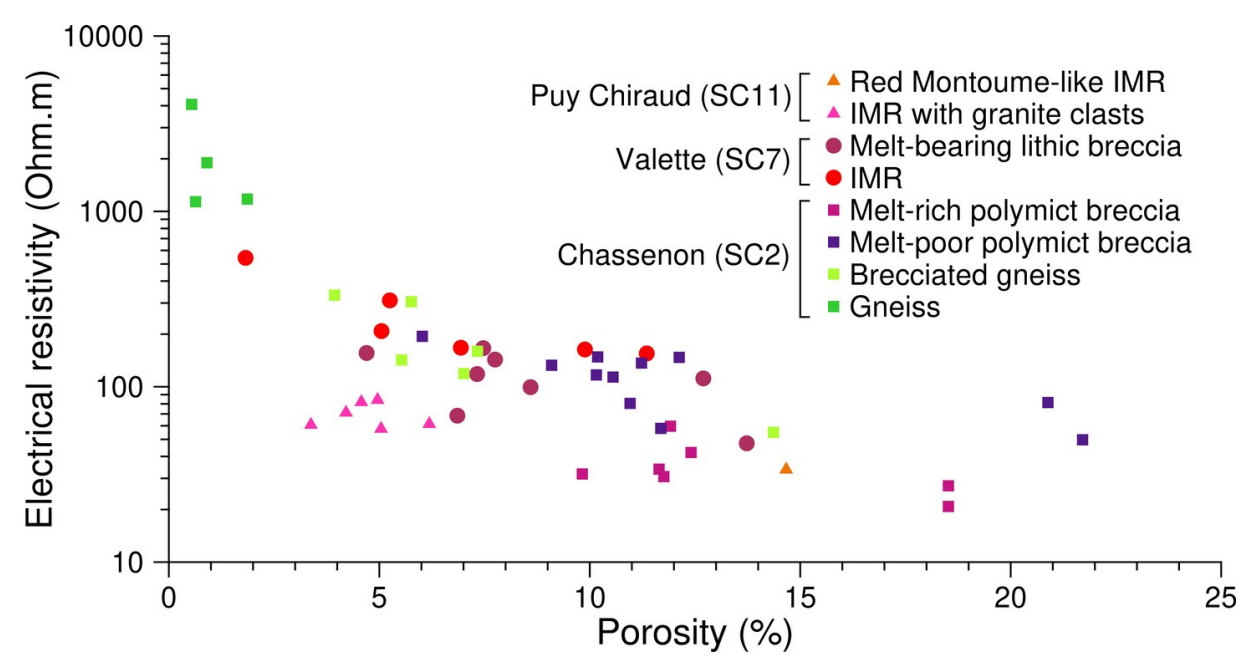

Figure 4. Electrical resistivity versus porosity of core samples from SC2 (Chassenon), SC7 (Valette), and SC11 (Puy Chiraud) drilling sites. 

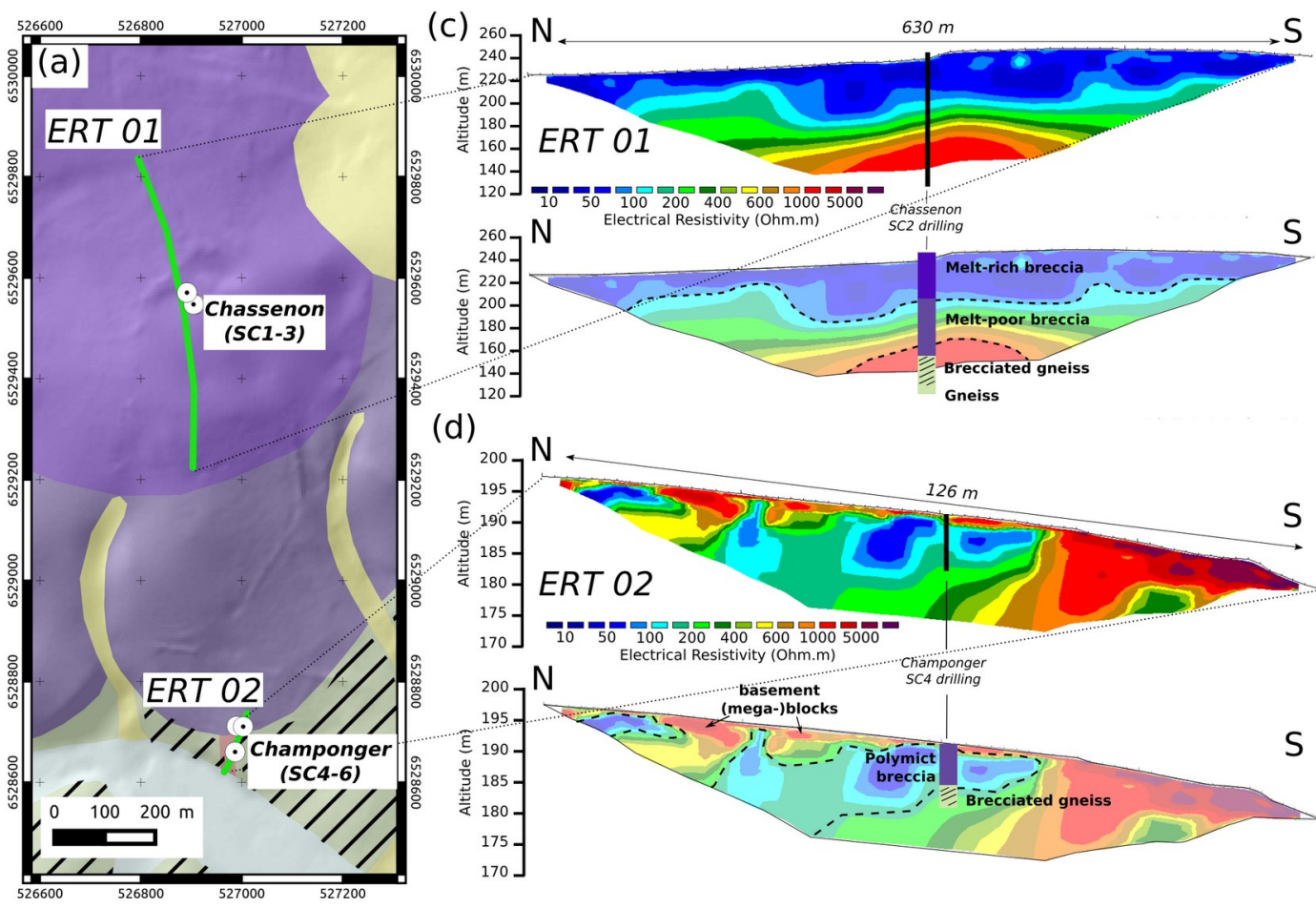

(d)
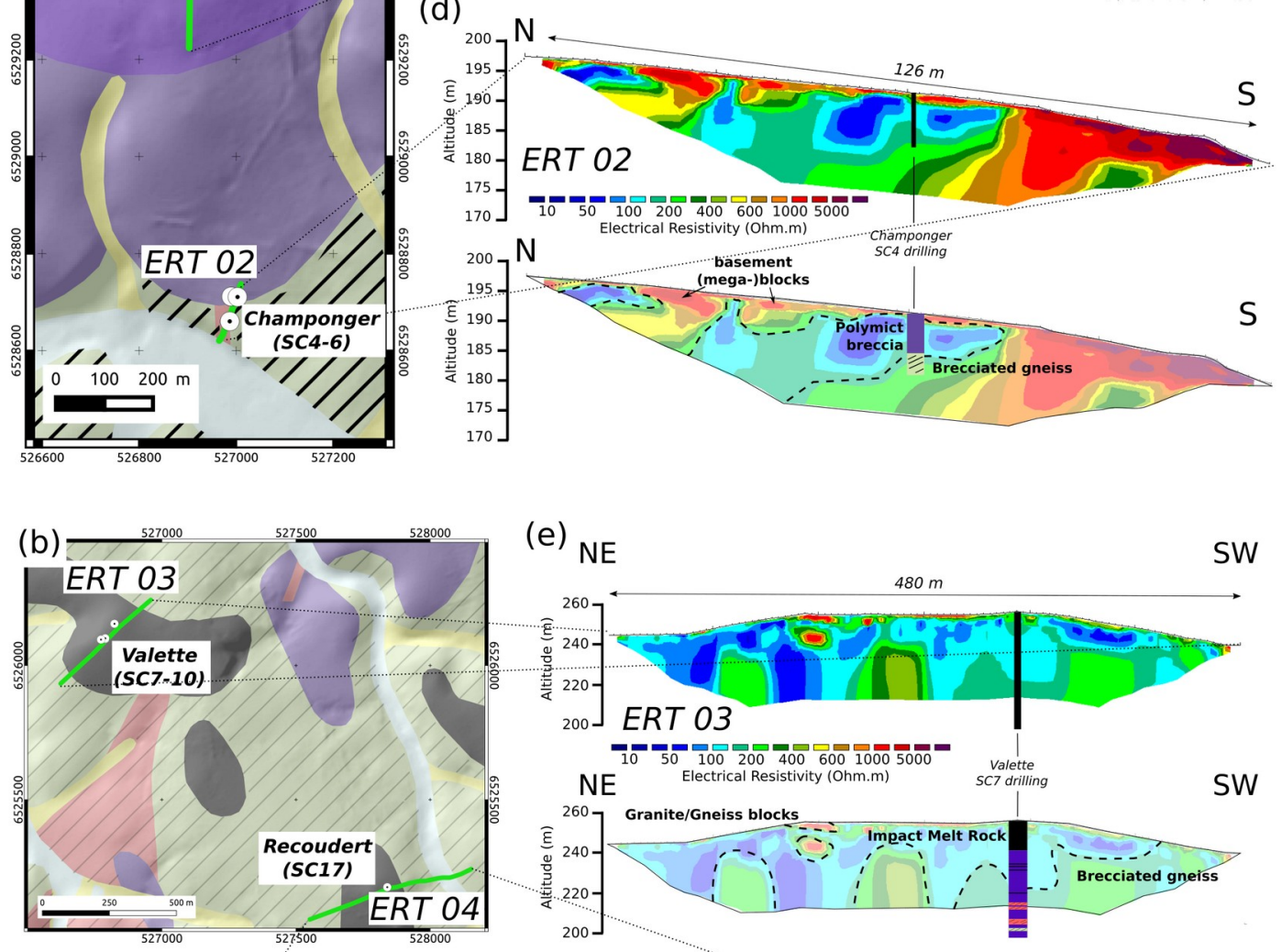

(e) NE

SW

(f)

WSW
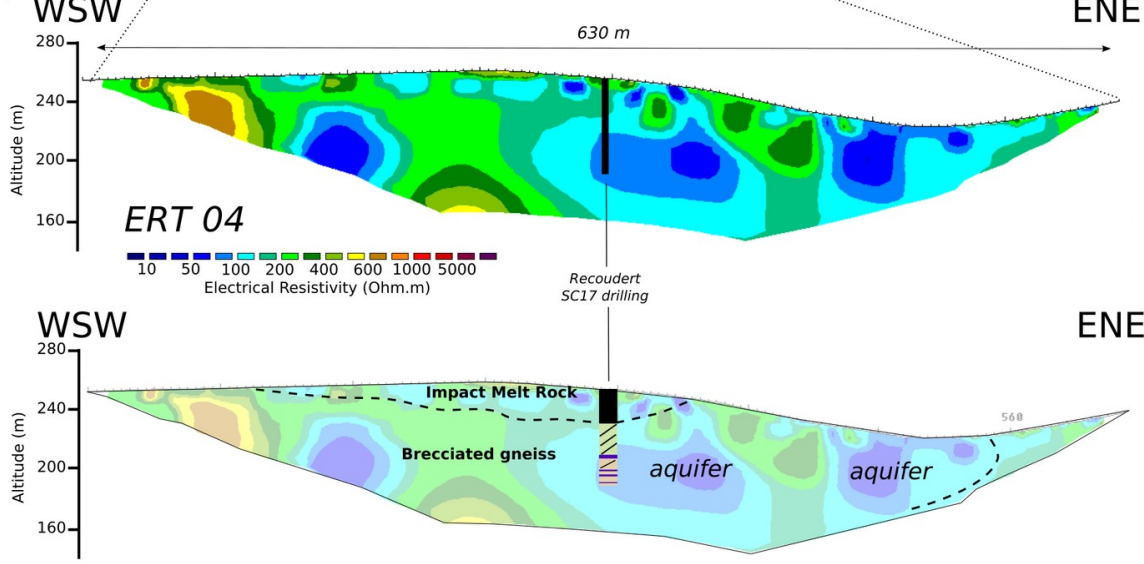

Figure 5. Location maps ( $a$ and $b$; see Figure 1 for legend) and electrical resistivity cross sections after inversion of ERTO1 (c), ERTO2 (d), ERTO3 (e), and ERTO4 (f) profiles' data (top), and associated geological interpretations (bottom) considering the lithologies observed in the corresponding drilling. See Figure S3 for other electrical resistivity tomography (ERT) profiles. 

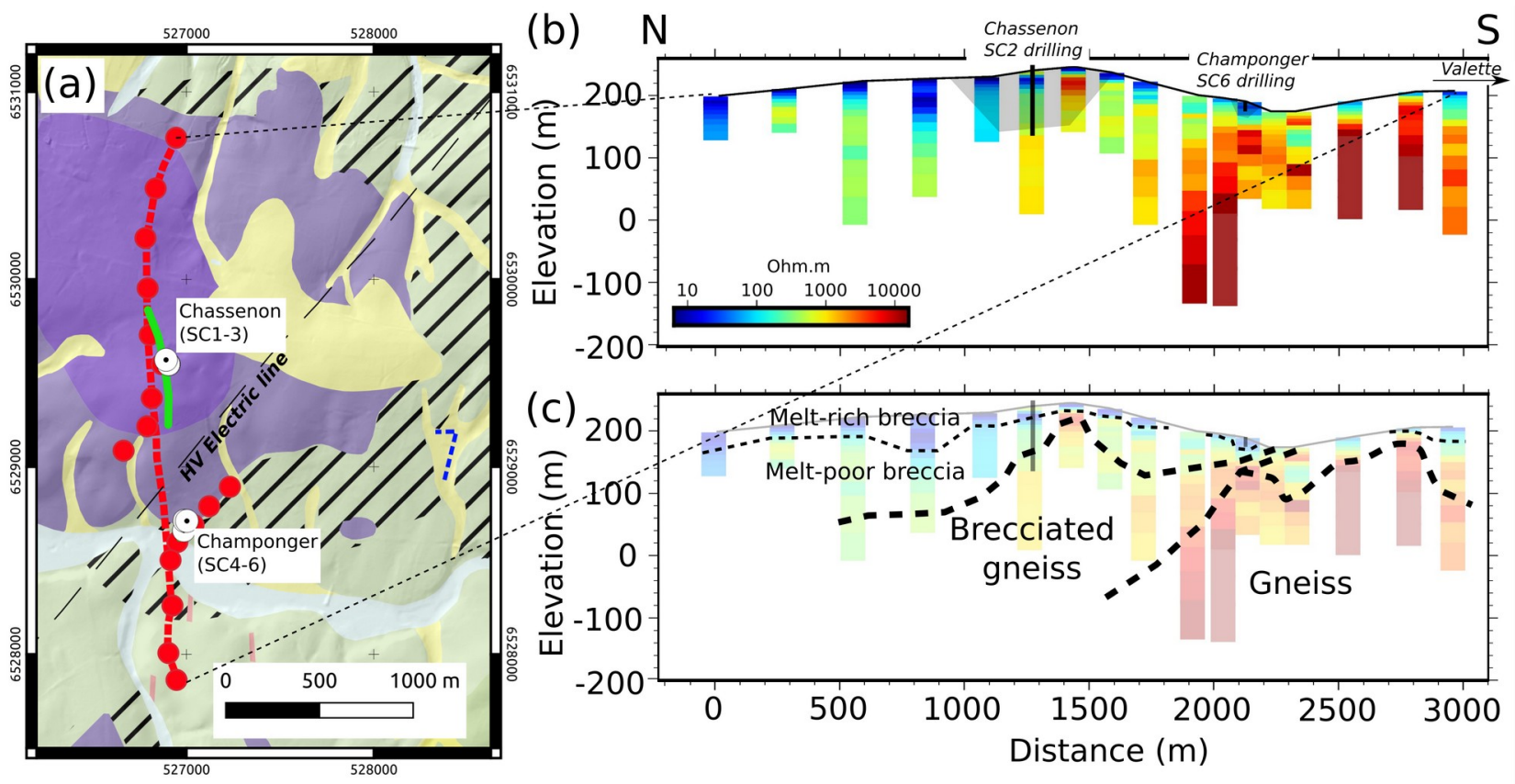

Figure 6. (a) Geological map (see legend in Figure 1) showing the location of controlled-source audio-magnetotelluric (CS-AMT) measurement sites (red disks) and the associated projected profile (dashed red line), the transmitter site (dashed blue line on the east), the electrical resistivity tomography (ERT) sections (green line) and drilling sites; (b) resulting electrical resistivity cross section after inversion of CS-AMT data from north of Chassenon to south of Champonger, with locations of ERT01 and 02 sections (shaded polygons), and SC2 and SC6 drilling sites; (c) same as (b) with our interpretations (dashed lines). The vertical exaggeration for these sections is 2.5 .

\section{Discussion}

\subsection{Electrical Properties of Impactites}

Our results suggest that the electrical resistivity decreases when the melt content (and its associated alteration product(s)) in breccia increases. It is confirmed by the downhole logging, laboratory measurements and ERT soundings performed at other drilling sites, including those where IMR crops out. This trend is linked to the porosity of these formations. Indeed the impact melt-rich breccia have significant porosities (>10\% on average; Figure 4). This behavior between the porosity/melt content and the electrical resistivity is slightly observed in the IMR too. In details, downhole logging over the Babaudus-like and Montoume-like IMR of the Rochechouart impact structure displays medium resistivity values, ranging between 100 and 1,000 Ohm.m. However, higher resistivities would have been expected for such type of massive deposits (Figure 4 showing porosities $<10 \%$ on average), even taking into account the presence of the water table. Indeed, several terrestrial impact structures show that some melt sheets are associated with electrical resistivities larger than those of the brecciated gneiss (i.e., >1,000 Ohm.m; Henkel, 1992). In the central uplift of the Araguainha impact structure (Brazil) with a mixed target, using ERT soundings only, Tong et al. (2010) observed low resistivities ( $<100 \mathrm{Ohm} . \mathrm{m}$ ) in porous polymict breccia, and relatively high resistivity anomalies in IMRs $(300-1,000 \mathrm{Ohm} . \mathrm{m}$ vs. $50-300 \mathrm{Ohm} . \mathrm{m}$ in Rochechouart). These resistive zones within Araguainha are interpreted as IMR "blocks" nearby the central uplift of the structure, and their crystalline/glassy matrix induces a lower porosity than the heterogeneous matrix of the polymict breccia (with microfractures). On the other hand, the IMR from the M0077 drilling site of the IODP-ICDP Exp 364 within the peak ring of the Chicxulub impact structure (Mexico; Morgan et al., 2016) show extremely low electrical resistivity values considering either multiscanner core logging data $(0.4-3.4 \mathrm{Ohm} . \mathrm{m})$ or downhole logging data using EM51 induction tool (3-6 Ohm.m; Gulick et al., 2017; Lofi et al., 2018; Morgan et al., 2017). The large porosities (about 20\%) of the Chicxulub IMR units and their saturation in saline water largely decrease their initial electrical resistivity. Despite fresh water saturation, the moderate resistivities 
observed in the IMR, and more largely in the melt-bearing breccia, of the Rochechouart impact structure should be explained by another process. A central negative Bouguer gravity anomaly of $-9 \mathrm{mGal}$ is observed over the whole area of impact deposits, with a minimum where the IMR outcrop in Valette and Babaudus (Pohl, 2015). It means that the whole column of rocks in these areas, including the IMR (Figures 3-5), is porous via fracturing and/or brecciation at all scales. Following the impact, for instance in the formations of the present-day Chassenon butte, fluid circulation may have been favored by fractures and connected porosity (see Figure S4 for an example in the brecciated gneiss of SC2 borehole). Associated with the heat stored in the impacted area, post-impact hydrothermalism led to an intense alteration of the melt into secondary phases, likely clays (Kukkonen et al., 1992; Lambert, 2010; Sapers et al., 2014). The latter minerals were also observed in the core samples from the peak-ring of Chicxulub, where the hydrothermal system seems to have been deeper, longer and in some places, more intense than expected (Kring et al., 2020). Impact melt glasses of the Chicxulub IMR were altered into clay minerals, in the form of smectites for example, and other minerals (Kring et al., 2020). On average, electrical resistivities associated to these IMR units seem to be slightly lower than the ones of the suevite (mean value of about 5 Ohm.m), as well as of the underlying units of granitoids (mean value of about 7 Ohm.m; Gulick et al., 2017; Morgan et al., 2017). Therefore the role of post-impact alteration of the melt could be significant to reduce the electrical resistivities of IMR. Preliminary petrographical analyses of some thin slices (work in progress) of the recent core samples from the Chassenon drilling site already reveal a significant amount of minerals typical of post-impact hydrothermal alteration, which was also previously described on field samples by Kukkonen et al. (1992), Lambert (2010), and Sapers et al. (2014). We thus suggest that this weathering is the reason of the high conductivities observed within the melt-rich breccia layer of Chassenon, even above the water table (clays remain wet). The first analyses of the core samples of IMR of other sites also revealed their heterogeneity and the presence of isolated vesicular textures which, combined with the general alteration, may explain their moderate electrical resistivity signal (Lambert et al., 2018, 2019). In the melt-poor (Rochechouart-like) breccia layer, electrical resistivities are larger, due to either a deeper burial, or less intense weathering, or just because the melt was less abundant. To date, no other electrical studies of impact structure formations were able to unveil such detailed electrical contrasts between melt-bearing and melt-poor impact breccia formations. It argues in favor of a more widespread use of the electrical methods over Rochechouart (perhaps outside the impactite area too) as well as over any (eroded) impact structures, for instance to map the melt content or alteration. However, more detailed petrographical and/or geochemical data are needed to better conclude on the amount and role of the clay (and perhaps other) minerals to influence the electrical resistivity properties.

Interestingly, the melt-rich breccia layer of Chassenon is also strongly magnetized compared to the underlying melt-poor breccia layer. Magnetic anomaly mapping in the vicinity of the Chassenon drilling site reveals strong gradients, as well as in Champonger at the border of the Chassenon butte (Figure S5) where the impactites and the underlying gneiss are fractured and mixed as blocks. This confirms the lateral heterogeneities unveiled by electrical resistivity investigations. The CS-AMT data also image the fracturing/brecciation in the basement with electrical resistivity values of 1,000-3,000 Ohm.m, lower than expected for crystalline rocks ( 5,000-10,000 Ohm.m). Bobée et al. (2010) mention electrical resistivities on the order of $600-800 \mathrm{Ohm} . \mathrm{m}$ for the brecciated basement beneath Chassenon, which is lower than the values revealed by our ERT soundings (1,000-3,000 Ohm.m). Henkel (1992) however reported higher resistivities (between 2,000 and $8,000 \mathrm{Ohm} . \mathrm{m}$ ) for brecciated crystalline rocks of the impacted Fennoscandian shield in Sweden, and resistivities exceeding 10,000 Ohm.m for the unaffected basement. It is also interesting to compare the electrical resistivity of the basement in the Chassenon area with the models given for Araguainha and Serra da Cangalha impact structures in Brazil (Adepelumi et al., 2005; Masero et 
al., 1997; Tong et al., 2010). For Araguainha (with a mixed target), the unaffected upper crust seems to have electrical resistivities on the order of 5,000 Ohm.m, while the depth of fracturing/brecciation may reach about $5 \mathrm{~km}$. For Serra da Cangalha (with a sedimentary target), Adepelumi et al. (2005) reported a weathered basement layer with resistivities on the order of 500 Ohm.m while the crystalline basement resistivity values are larger than 2,000 Ohm.m. Such values are observed at depth in the valley between Chassenon and Valette impactite areas (southern part of Figures $6 \mathrm{~b}$ and $6 \mathrm{c}$ ), which could be linked to the presence of an unbrecciated gneissic basement too.
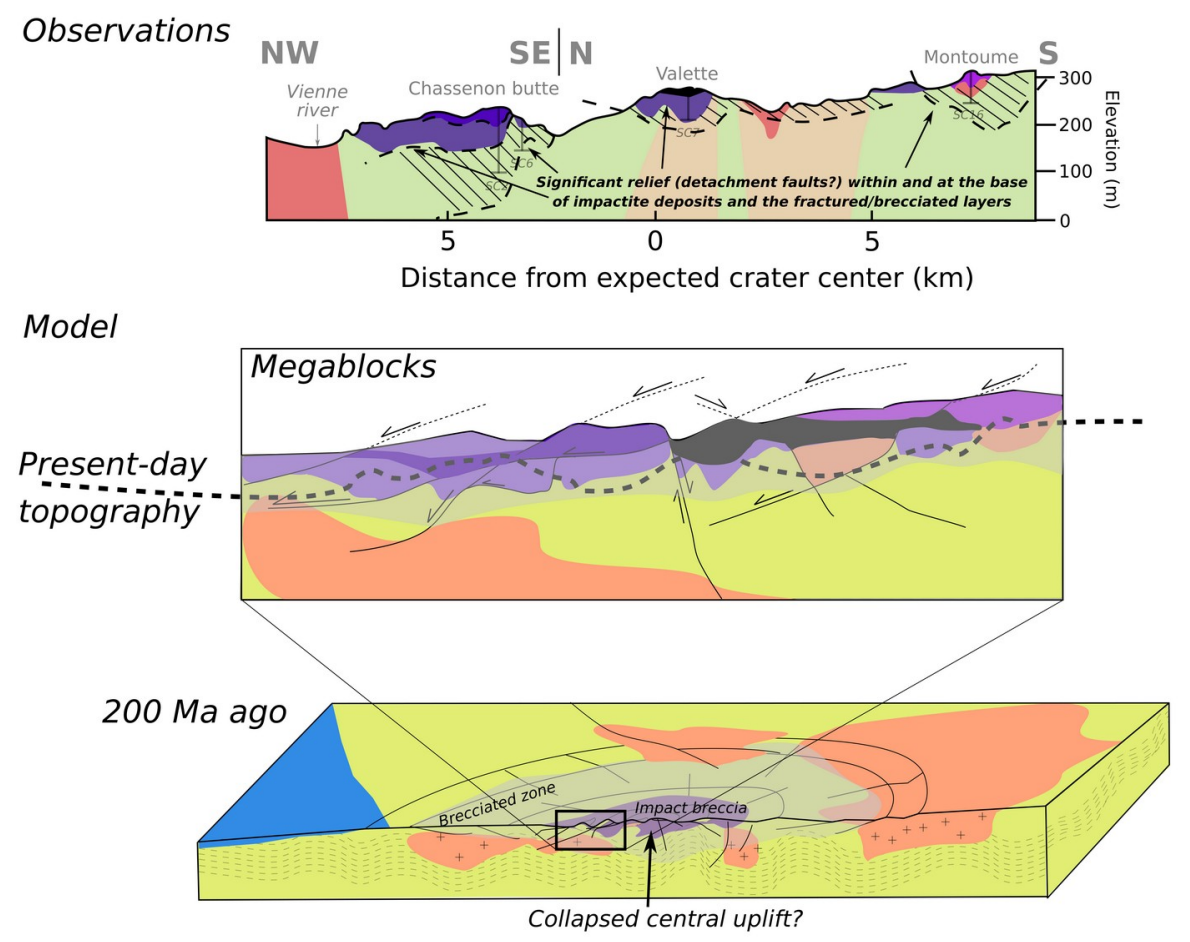

Figure 7. (Top) Geological cross section of Figure 1, with constraints from this study, (middle) interpreted schematic $2 D$ model of the Chassenon area (showing megablocks and tilting), and (bottom) its eventual position within the whole Rochechouart impact structure about 200 Ma ago.

\subsection{Geometry of Impactite Deposits}

As already mentioned, the bottom of the Rochechouart impact crater, which today is exposed in outcrops, should not be considered as a regular and flat interface. Indeed, we characterized and quantified local relief within the impactite layers (maybe due to lateral non-uniform mixing processes), between impactites and gneiss, as well as between the brecciated/fractured and unaffected basement (Figures 5-7). Bobée et al. (2010) already reported some of these features using interpretations of shallow EM data over a smaller area of the Chassenon butte. These rough topographies derived from the electrical resistivity stratigraphy reflect the creation (by fracturing and brecciation), the sliding/collapsing along faults, and the final emplacement of, megablocks during the modification stage of the impact event (Kenkmann et al., 2014; Lambert, 1977; Osinski \& Pierazzo, 2013). This phase may be associated with a collapsing central uplift or with a terrace zone (Figure 7; Lambert, 2010). The former is more likely than the latter since we mainly observed interfaces (or faults) dipping outwardly (see below). In this case, the observed amplitudes, with 40-50 $\mathrm{m}$ high reliefs on the ERT sections and $>100 \mathrm{~m}$ in the CS-AMT section could reflect the presence of such megablocks and would thus provide an estimate of their minimum size. The presence of megablocks and the complex stratigraphical relationships between the impactites and the basement in the Chassenon area may also be consistent with the existence of an eventual 
general tilting of the whole structure. Indeed Lambert (2010) pointed the fact that the bottom of the final crater may have been inclined by $0.6^{\circ}$ toward North (potentially due to pre-existing reliefs), resulting in preferential erosion of the impactite deposits in the south. Interestingly, the CS-AMT electrical resistivity logs show that the surface separating the impactites and brecciated basement is dipping northward at an angle of about $10^{\circ}$ (Figure 6), or maybe less, as seen in the ERT cross sections (Figure 5). Henkel (1992) mentioned that for "large" complex craters, the outer edge of the brecciation is associated to significant electrical resistivity variations and seems to be buried under (mega-)breccia ring (see also Kenkmann et al., 2014). Our electrical resistivity observations of uneven reliefs in the impactite deposits and basement are consistent with the presence of mega-breccia formations, which may have moved laterally, perhaps through the preexisting topography and/or northward-dipping fractures/faults. These movements may have occurred during a preferentially outwarding collapse of a temporary central uplift, which is not remaining in Rochechouart (Figure 7), while systematically observed for medium-size structures in crystalline target. It may then be an intermediate structure with a "(partially)collapsed" central uplift, which may explain megablock displacements (see Baker et al., 2011, for some examples of transitional craters). This aspect could be investigated by $2 \mathrm{D} / 3 \mathrm{D}$ modeling of the structure using constraints from potential-field data and/or from seismic cross sections, but also by performing further specific numerical simulations of impacts on crystalline targets with pre-existing fractures and/or topography.

\section{Conclusions}

This study aims at using electrical resistivity observations at different scales to reveal lithological and geometrical variations within the Rochechouart impact structure, the latter showing the bottom of a medium-size impact crater in a crystalline target. Logging investigations within recent boreholes, associated to core sample measurements, first described that each impactite formation has their own specific electrical resistivity properties where more melt, and/or its alteration products like clays increases the conductivity. We also observed that the electrical resistivity also decreases with porosity. These first observations helped to extrapolate the lithologies observed within the boreholes using ERT. The latter image up to $50 \mathrm{~m}$ local relief of the interfaces between each impactite formations (in particular between the melt-rich and melt-poor impact breccia), revealing geometries compatible with megablocks emplacements. This is confirmed by CS-AMT observations which show northward-dipping electrical resistivity contrasts between the meltbearing breccia layer and the brecciated and unbrecciated basement. All these observations support an impact structure briefly possessing a central uplift which may have collapsed through megablocks sliding.

\section{Data Availability Statement}

The data supporting the conclusions of this study can be downloaded here: https://doi.org/10.34930/be0549d1-e876-49c5-b07f-bf04d398b25e (electrical resistivity logging data and laboratory measurements on samples, apparent electrical resistivity data of ERT cross sections, and CS-AMT inverted data).

\section{Acknowledgments}

This work was supported by the Programme National de Planétologie (PNP) of CNRS/INSU, cofunded by CNES, as well as by $A^{*}$ Midex foundation from Aix-Marseille University. It is part of the CIRIR program and benefited from the field expertise and the logistical support of the CIRIR on site. The authors thank the Reserve Naturelle Nationale de l'Astroblème de Rochechouart Chassenon, for allowing the field work carried out on its territories. The authors also acknowledge ANR project EQUIPEX CRITEX (grant \# ANR-11-EQPX-0011) for its financial support to the CS-AMT equipment. B. 
Célérier, G. Henry, L. Brun, and J. Paris are thanked for the downhole logs acquisition, while L. Hervieu, O. Cherait, G. Telansamou, who were students in training internships at the time of the surveys, F. Demory and J. Gattacceca, are warmly acknowledged too. Lastly, we thank the editor J. Feinberg for his support and suggestions, and the two anonymous reviewers who greatly contributed to improve the manuscript.

\section{References}

- Adepelumi, A. A., Fontes, S. L., Schnegg, P. A., \& Flexor, J. M. (2005). An integrated magnetotelluric and aeromagnetic investigation of the Serra da Cangalha impact crater, Brazil. Physics of the Earth and Planetary Interiors, 150, 159-181. https://doi.org/10.1016/i.pepi.2004.08.029

- Baker, D. M. H., Head, J. W., Schon, S. C., Ernst, C. M., Prockter, L. M., Murchie, S. L., et al. (2011). The transition from complex crater to peak-ring basin on Mercury: New observations from MESSENGER flyby data and constraints on basin formation models. Planetary and Space Science, 59, 1932-1948. https://doi.org/10.1016/j.pss.2011.05.010

- Bobée, C., Schmutz, M., Camerlynck, C., \& Robain, H. (2010). An integrated geophysical study of the western part of the Rochechouart-Chassenon impact structure, Charente, France. Near-Surface Geophysics, 8, 259-270. https://doi.org/10.3997/1873-0604.2010011

- Chèvremont, P., \& Floc'h, J.-P. (1996). Carte géologique de la France à 1/50 000, Rochechouart (Vol. 687). BRGM.

- Cohen, B. E., Mark, D. F., Lee, M. R., \& Simpson, S. L. (2017). A new high-precision 40 Ar/ 39 Ar age for the Rochechouart impact structure: At least $5 \mathrm{Ma}$ older than the Triassic-Jurassic boundary. Meteoritics \& Planetary Sciences, 52, 1600-1611. https://doi.org/10.1111/maps.12880

- Gulick, S., Morgan, J., Mellett, C. L., Green, S. L., Bralower, T., Chenot, E., et al. (2017). Site M0077: Upper peak ring. In J. Morgan, S. Gulick, C. L. Mellett, S. L. Green, \& the Expedition 364 Scientists. (Eds.), Chicxulub: Drilling the K-Pg impact crater (Vol. 364). Proceedings of the International Ocean Discovery Program. https://doi.org/10.14379/iodp.proc.364.106.2017

- Henkel, H. (1992). Geophysical aspects of meteorite impact craters in eroded shield environment, with special emphasis on electric resistivity. Tectonophysics, 216, 63-89. https://doi.org/10.1016/0040-1951(92)90156-Z

- Kenkmann, T. (2021). The terrestrial impact crater record: A statistical analysis of morphologies, structures, ages, lithologies, and more. Meteoritics \& Planetary Sciences, 56(5), 1024-1070. https://doi.org/10.1111/maps.13657

- Kenkmann, T., Poelchau, M. H., \& Wulf, G. (2014). Structural geology of impact craters. Journal of Structural Geology, 62, 156-182. https://doi.org/10.1016/i.jsg.2014.01.015

- Kraut, F., \& French, B. (1971). The Rochechouart meteorite impact structure, France: Preliminary geological results. Journal of Geophysical Research, 76, 5407-5413. https://doi.org/10.1029/JB076i023p05407

- Kring, D. A., Tikoo, S. M., Schmieder, M., Riller, U., Rebolledo-Vieyra, M., Simpson, S. L., et al. (2020). Probing the hydrothermal system of the Chicxulub impact crater. Science Advances, 6(22), eaaz3053. https://doi.org/10.1126/sciadv.aaz3053

- Kukkonen, I. T., Kivekäs, L., \& Paananen, M. (1992). Physical properties of karnaite (impact melt), suevite and impact breccia in the Lappajarvi meteorite crater, Finland. Tectonophysics, 216, 111122. https://doi.org/10.1016/0040-1951(92)90159-4

- Lambert, P. (1977). Les effets des ondes de choc naturelles et artificielles, et le cratère d'impact de Rochechouart (Limousin France) (Thèse d'État, p. 515). Université de Paris Sud, Centre d'Orsay. - Lambert, P. (2010). Target and impact deposits at Rochechouart impact structure, France. In R. L. Gibson, \& W. U. Reimold (Eds.), Large meteorite impacts and planetary evolution IV (Vol. 465, pp. 
509-541). Geological Society of America Special Paper. https://doi.org/10.1130/2010.2465(2510.1130/2010.2465(25)

- Lambert, P., Alwmark, C., Baratoux, D., Bouley, S., Brack, A., Bruneton, P., et al. (2018). Rochechouart 2017-Drilling campaign: First results. Paper presented at 49th Lunar and Planetary Science Conference, LPI Contrib. No. 2083. Retrieved from https://www.hou.usra.edu/meetings/lpsc2018/pdf/1954.pdf

- Lambert, P., Alwmark, C., Baratoux, D., Bouley, S., Brack, A., Bruneton, P., et al. (2019). The Rochechouart 2017-Cores rescaled: Major features. Paper presented at 50th Lunar and Planetary Science Conference, LPI Contrib. No. 2132. Retrieved from https://www.hou.usra.edu/meetings/lpsc2019/pdf/2005.pdf

- Lofi, J., Smith, D., Delahunty, C., Le Ber, E., Brun, L., Henry, G., et al. (2018). Drilling-induced and logging-related features illustrated from IODP-ICDP Expedition 364 downhole logs and borehole imaging tools. Scientific Drilling, 24, 1-13. https://doi.org/10.5194/sd-24-1-2018

- Masero, W., Fischer, G., \& Schnegg, P. A. (1997). Electrical conductivity and crustal deformation from magnetotelluric results in the region of the Araguainha impact, Brazil. Physics of the Earth and Planetary Interiors, 101, 271-289. https://doi.org/10.1016/S0031-9201(96)03267-0

- Melosh, H. J. (1989). Impact cratering: A geologic process. Oxford University Press.

- Morgan, J. V., Gulick, S. P. S., Bralower, T., Chenot, E., Christeson, G., Claeys, P., et al. (2016). The formation of peak rings in large impact craters. Science, 354(6314), 878-882. https://doi.org/10.1126/science.aah6561

- Morgan, J. V., Gulick, S. P. S., Mellett, C. L., Green, S. L., Bralower, T., Chenot, E., et al. (2017). Site M0077: Introduction. In J. Morgan, S. Gulick, C. L. Mellett, S. L. Green, \& the Expedition 364 Scientists. (Eds.), Chicxulub: Drilling the K-Pg impact crater (Vol 364). Proceedings of the International Ocean Discovery Program. https://doi.org/10.14379/iodp.proc.364.103.2017

- Osinski, G. R. O., Grieve, R. A. F., Collins, G. S., Marion, C., \& Sylvester, P. (2008). The effect of target lithology on the products of impact melting. Meteoritics \& Planetary Sciences, 43(12), 19391954. https://doi.org/10.1111/i.1945-5100.2008.tb00654.x

- Osinski, G. R. O., \& Pierazzo, E. (2013). Impact cratering: Processes and products (1st ed., p. 330). Blackwell Publishing Ltd.

- Pilkington, M., \& Grieve, R. A. F. (1992). The geophysical signature of terrestrial impact craters. Reviews of Geophysics, 30(2), 161-181. https://doi.org/10.1029/92RG00192

- Pohl, J. (2015). Modelling the gravity anomaly of the Rochechouart impact structure (p. 1052). Paper presented at Bridging the Gap III: Impact cratering in nature, experiments and modeling, LPI $\begin{array}{llll}\text { Contribution } & \text { No. } & \text { Retrieved } & \text { from }\end{array}$ https://www.hou.usra.edu/meetings/gap2015/pdf/1052.pdf

- Pohl, J., Ernstson, K., \& Lambert, P. (1978). Gravity measurements in the Rochechouart impact structure (France). Meteoritics, 13, 601-604. https://doi.org/10.1111/maps.1978.13.issue-2

- Rasmussen, C., Stockli, D. F., Erickson, T. M., \& Schmieder, M. (2020). Spatial U-Pb age distribution in shock-recrystallized zircon-A case study from the Rochechouart impact structure, France. Geochimica et Cosmochimica Acta, 273, 313-330. https://doi.org/10.1016/j.gca.2020.01.017

- Sapers, H., Osinski, G. R., Banerjee, N. R., Ferrière, L., Lambert, P., \& Izawa, M. R. M. (2014). Revisiting the Rochechouart impact structure, France. Meteoritics \& Planetary Sciences, 49(12), 2152-2168. https://doi.org/10.1111/maps.12381

- Schmidt, T. (1984). Bearbeitung und Auswertung von Schweremessungen im Gebiet der ImpaktStruktur von Rochechouart (Massif Central, Frankreich) (Diploma thesis). University of Munich.

- Schmieder, M., Buchner, E., Schwarz, W. H., Trieloff, M., \& Lambert, P. (2010). A Rhaetian 40 Ar/ $39 \mathrm{Ar}$ age for the Rochechouart impact structure (France) and implications for the latest Triassic sedimentary record. Meteoritics \& Planetary Sciences, 45(8), 1225-1242. https://doi.org/10.1111/j.1945-5100.2010.01070.x 
- Tong, C. H., Lana, C., Marangoni, Y. R., \& Elis, V. R. (2010). Geoelectric evidence for centripetal resurge of impact melt and breccias over central uplift of Araguainha impact structure. Geology, 38(1), 91-94. https://doi.org/10.1130/G30459.1 